\title{
Early Enhancement of Fluid Transport in Rabbit Proximal Straight Tubules after Loss of
}

\section{Contralateral Renal Excretory Function}

\author{
Kaoru Tabei, David J. Levenson, and Barry M. Brenner, Laboratory of Kidney \\ and Electrolyte Physiology and Department of Medicine, Brigham and \\ Women's Hospital and Harvard Medical School, Boston, Massachusetts 02115
}

A B S TR A C T To assess the renal functional adaptation to reduced excretory capacity, we studied whole kidney and single nephron function in anesthetized volume-replete rabbits after unilateral (left kidney) nephrectomy (UNX), ureteral obstruction (UO), or ureteroperitoneostomy (UP). At $24 \mathrm{~h}$, despite the absence of measurable hypertrophy of the contralateral (right) kidney, these procedures significantly increased $p$-aminohippurate clearance $(45-54 \%)$ and inulin clearance $\left(C_{\mathrm{IN}}\right)(64-110 \%)$ compared with sham-operated control animals. In each group, whole kidney sodium reabsorption increased in proportion to the rise in $C_{\mathrm{IN}}$.

To determine whether the intrinsic transport capacity of proximal tubule segments is altered by these maneuvers, we measured fluid volume reabsorption rate $(J v)$ in isolated superficial proximal straight tubule (PST) segments perfused in vitro, comparing each control tubule (obtained by biopsy of the left kidney immediately before an experimental maneuver) with a corresponding tubule segment obtained $24 \mathrm{~h}$ or $7 \mathrm{~d}$ later from the contralateral kidney. Control tubule $\mathrm{Jv}$ in sham-24 $\mathrm{h}$ animals averaged $0.48 \pm 0.04 \mathrm{nl} /(\mathrm{min}$. $\mathrm{mm})$. Jv did not change significantly at $24 \mathrm{~h}$ or $7 \mathrm{~d}$ after sham maneuvers but increased significantly at 24 $\mathrm{h}$ after $\mathrm{UNX}[\Delta J \mathrm{v}=0.13 \pm 0.03 \mathrm{nl} /(\mathrm{min} \cdot \mathrm{mm})]$, UO $[\Delta J \mathrm{v}=0.10 \pm 0.04 \mathrm{nl} /(\mathrm{min} \cdot \mathrm{mm})]$, and $\mathrm{UP}[\Delta J \mathrm{v}$ $=0.13 \pm 0.04 \mathrm{nl} /(\mathrm{min} \cdot \mathrm{mm})] . J \mathrm{v}$ remained increased by similar amounts at $7 \mathrm{~d}$ after UNX and UO. To evaluate whether an increase in glomerular filtration rate (GFR) might be the stimulus to this augmentation in $J v$ val-

A preliminary abstract was presented at the 14th Annual Meeting of the American Society of Nephrology, Washington, DC, 22-24 November 1981

Received for publication 6 June 1982 and in revised form 18 May 1983. ues, methylprednisolone (MP) (15 $\mathrm{mg} / \mathrm{kg}$ per d) was administered daily to sham-operated animals, a maneuver which induced a $73 \%$ rise in $C_{\text {IN }}$ by day 5 . This procedure also produced a significant increase in $\mathrm{Jv}$ in PST at $5 \mathrm{~d}[\Delta J \mathrm{v}=0.16 \pm 0.05 \mathrm{nl} /(\mathrm{min} \cdot \mathrm{mm})]$. The increase in $\mathrm{Jv}$ evident in each group at 5 or $7 \mathrm{~d}$ was paralleled by an equivalent change in tubule cell volume and apparent tubule luminal surface area in UNX-7d and MP-5d; no such increments in these indices, or in apparent tubule serosal surface area were evident at $24 \mathrm{~h}$ in any group.

Thus, a $50 \%$ reduction in renal excetory function in the rabbit provokes adjustments in renal plasma flow rate and GFR in the contralateral kidney, which are evident by $24 \mathrm{~h}$. The concurrent change in $\mathrm{Jv}$ in PST is closely related to $C_{\mathrm{IN}}$ or some associated hemodynamic process, but does not appear to require an increase in tubule cell volume or apparent surface area. The ability to detect these small in vivo changes in $J v$ may derive from the enhanced sensitivity of pairedkidney experiments using tubule segments obtained by renal biopsy.

\section{INTRODUCTION}

Reduction of renal mass is usually followed by adaptive increases in the size and function of the remnant kidney that serve to mitigate the disturbances of salt and water balance that would otherwise be likely to ensue (1). Although the chronic adjustments in nephron size $(2,3)$, glomerular filtration rate $(\text { GFR })^{1}(3-7)$,

\footnotetext{
${ }^{1}$ Abbreviations used in this paper: $A_{\mathrm{L}}$, apparent tubule luminal surface area; $A_{s}$, apparent tubule serosal surface area; $\mathrm{BW}$, body weight; $\mathrm{C}$, control tubule; $C_{\mathrm{IN}}$, inulin clearance; $C_{\mathrm{PAH}}$, PAH clearance; EXP, experimental tubule; $\mathrm{FE}_{\mathrm{Na}}$, fractional sodium excretion; GFR, glomerular filtration rate; ID, tubule inner diameter; $J v$, net fluid volume
} 
and tubule sodium and water reabsorption (7-12) that result have been well studied, less attention has been paid to the early alterations in renal function and morphology that follow loss of functional renal tissue. Recent studies indicate that within several hours after unilateral nephrectomy (UNX) in volume-replete animals, the remaining kidney exhibits a significant rise in GFR and filtered load of sodium $(13,14)$. Because only a small fraction of the increment in filtered sodium is excreted in the urine, it may be deduced that whole kidney sodium reabsorption $\left(T_{\mathrm{Na}}\right)$ rises during this acute period. A variety of hemodynamic and hormonal alterations contribute to this phenomenon, but an increase in the intrinsic fluid reabsorptive capacity of tubule segments may also be an important factor. Such increases have been demonstrated by in vitro perfusion of isolated proximal straight tubule (PST) and proximal convoluted tubule (PCT) segments obtained from rabbits weeks to months after reduction in nephron mass $(15,16)$. Since increases in tubule weight and luminal surface area were also observed in the PCT segments (16), tubule hypertrophy was suggested to be the mechanism underlying these chronic adaptations in tubule sodium reabsorption.

To assess the relationship between the early functional and hypertrophic responses, we performed clearance and in vitro tubule perfusion studies in rabbits $24 \mathrm{~h}$ and $7 \mathrm{~d}$ after elimination of unilateral renal excretory function. Regardless of the technique used to abolish unilateral excretory function-UNX, unilateral ureteral ligation (UO), or unilateral ureteroperitoneostomy (UP)-GFR and $T_{\mathrm{Na}}$ were increased. The rise in $T_{\mathrm{Na}}$ that resulted from these maneuvers, or from administration of methylprednisolone (MP), was accompanied by an increase in the in vitro fluid reabsorption rate $(\mathrm{Jv})$ of PST segments. Although tubule hypertrophy may account for the augmented $J \mathrm{v}$ values seen $7 \mathrm{~d}$ after loss of contralateral renal function, this mechanism does not appear to explain the early increases in $J v$ which were demonstrated at $24 \mathrm{~h}$.

\section{METHODS}

General. Since animal-to-animal variations in net transtubular fluid transport in PST contribute to the variability

reabsorption rate; $\mathrm{MP}$, methylprednisolone; $\mathrm{Pa}$, mean arterial blood pressure; $\mathrm{PAH}, \boldsymbol{p}$-aminohippurate; $\mathrm{PCT}$, proximal convoluted tubule; $\mathrm{PD}$, transepithelial electrical potential difference; $P_{N a}$, plasma sodilim concentration; PST, proximal straight tubule; RtKW, right kidney wet weight; $T_{\mathrm{Na}}$, whole kidney sodium reabsorption rate; $U_{\mathrm{Na}} \mathrm{V}$, urinary sodium excretion rate; UNX, unilateral nephrectomy; UO, unilateral ureteral ligation; UP, unilateral ureteroperitoneostomy; VOL, tubule cell volume. in measured $J v$ values, we developed a technique that permits paired comparison of results from the same animal before and after experimental manipulations. In each animal, the initial control tubule (C) was dissected from tissue obtained by open left renal biopsy immediately before the experimental maneuver; the experimental tubule (EXP) was obtained $24 \mathrm{~h}, 5 \mathrm{~d}$, or $7 \mathrm{~d}$ later from the right kidney. Clearance studies were performed on an unpaired basis 1 or $5 \mathrm{~d}$ after the experimental manipulation; animal preparation, including open biopsy, was in all respects the same as for in vitro tubule perfusion.

Animal preparation. Female New Zealand white rabbits weighing $1.25-2.27 \mathrm{~kg}$ were housed in temperature-controlled quarters and were fed standard rabbit chow (Charles River Formula, Agway-Country Foods, Agway Inc., Waverly, NY). Animals were anesthetized with pentobarbital sodium (Nembutal, Abbott Laboratories, North Chicago, IL), 20-25 mg/kg body wt i.v., and the left kidney was exposed retroperitoneally via a flank incision. A small longitudinal wedge biopsy specimen (10-15-mm long by $1.5-2.0-\mathrm{mm}$ wide by $7-\mathrm{mm}$ deep) was obtained from the midline of the kidney surface by making parallel incisions with a scalpel blade, and cutting the medullary pole of the specimen with a pair of right-angle forceps introduced into the incisions. The specimen was used for in vitro perfusion experiments (C) or discarded if clearance studies were subsequently performed. Hemostasis was established within 1-2 min by packing the biopsy site with an absorbable gelatin sponge (Gelfoam, Upjohn Co., Kalamazoo, MI); specific experimental manipulations were then performed (see below). The animals regained consciousness within $2-3 \mathrm{~h}$ and were given free access to food and water.

Experimental manipulations that followed immediately after left renal biopsy included $(a)$ sham: the ipsilateral renal pedicle was manipulated and the flank incision was then closed with 2-0 silk sutures (26 rabbits); (b) UNX: ipsilateral nephrectomy was performed before closure of the flank incision ( 26 rabbits); (c) UO: the ipsilateral ureter was occluded by a ligature placed just below the renal pelvis and the incision was then closed (26 rabbits); (d) UP: a $3-\mathrm{cm}$ length of silicone elastomer tubing, $1.2 \mathrm{~mm}$ o.d. (Retract-O-Tape, Med-Pro Division, Quest Medical Inc., Carrolton, TX), was inserted into the ipsilateral ureter $1-2 \mathrm{~cm}$ below the renal pelvis. The distal end of the catheter was inserted into the peritoneum, thereby creating a UP, after which the flank incision was closed (18 rabbits). Eight additional rabbits in this group were subsequently found to have peritonitis or catheter obstruction within $24 \mathrm{~h}$ and were discarded; $(e)$ normal: these unoperated animals served as additional controls in clearance experiments only (six rabbits); $(f)$ MP: after closure of the flank incision, MP sodium succinate, (SoluMedrol, Upjohn Co.) was administered intramuscularly in $0.9 \%$ saline in a dose of $15 \mathrm{mg} / \mathrm{kg}$ per $\mathrm{d}$ for 4 consecutive d (15 rabbits); ( $g$ ) MP-control: animals were prepared as for MP, but received daily injections of $0.9 \% \mathrm{NaCl}$ instead of MP for 4 consecutive $\mathrm{d}$ (five rabbits).

Evaluation of the right kidney by clearance study or in vitro tubule perfusion was performed at $24 \mathrm{~h}$ in sham-24 h, UO-24 h, and UP-24 h groups. In vitro perfusion of PST segments from the right kidney was also performed at $7 \mathrm{~d}$ in sham-7 d, UNX-7 d, and UO-7 d groups. UP animals were not studied at $7 \mathrm{~d}$. Right kidney clearance and in vitro tubule perfusion studies were performed in MP-5 d and MP-control$5 \mathrm{~d}$ groups at $5 \mathrm{~d}$, an interval known to be sufficient for MP to induce significant increases in GFR in the rat (17).

At the time of the right kidney studies, animals were weighed and again anesthetized with pentobarbital. For in 
vitro perfusion studies (experimental tubule), the right kidney was immediately removed, and several 1-2-mm-thick transverse midline slices were obtained and dissected as described below. For clearance studies, the right kidney was left in place and the animal was prepared as described below.

Clearance studies. After induction of anesthesia, a tracheostomy was performed, the left femoral artery and vein were catheterized with PE 50 tubing (Becton, Dickinson and Co., Parsippany, NJ) and the venous hematocrit was determined. A small suprapubic incision was made and a silastic catheter was inserted into the distal right ureter for collection of urine. A sample of urine was aspirated from the bladder for sodium determination. Rabbit serum (M.A. Bioproducts, Walkersville, MD) was infused via femoral vein at a rate of $33 \mathrm{ml} / \mathrm{h}$ for $10-14 \mathrm{~min}$ until a total of $0.4 \%$ body wt had been delivered. Thereafter, a maintenance infusion of plasma was given at the rate of $3.1 \mathrm{ml} / \mathrm{h}$ for the duration of the experiment. A solution containing $14 \mathrm{mg} / \mathrm{ml} p$-aminohippurate (PAH, Merck, Sharp and Dohme, Division of Merck and Co., Inc., West Point, PA) and $70 \mathrm{mg} / \mathrm{ml}$ inulin (Arnar-Stone Lab., Inc., Mt. Prospect, IL) in $0.9 \% \mathrm{NaCl}$ was also infused by femoral vein throughout the experiment maintaining plasma PAH concentration below $4 \mathrm{mg} / 100 \mathrm{ml}$. Mean arterial blood pressure $(\overline{\mathrm{P}} \mathrm{a})$ was measured in the femoral artery via a pressure transducer (Statham Model P23Db, Gould Statham Instruments Co., Hato-Ray, Puerto Rico) and recorded on a strip-chart recorder (Gould Brush 2200, Gould Inc., Cleveland, $\mathrm{OH}$ ). In most experiments, $\overline{\mathrm{P}}$ a fell by $10-20$ $\mathrm{mmHg}$ during the first 30-60 min after blood pressure recording was begun and then became stable. Rabbits in which $\overline{\mathrm{P}} \mathrm{a}$ fell by $30 \mathrm{mmHg}$ or more, or in which mean $\overline{\mathrm{P}}_{\mathrm{a}}$ was $<70 \mathrm{mmHg}$, were discarded. After a $90-120-\mathrm{min}$ equilibration period, three or four timed urine collections $(10 \mathrm{~min}$ each) were obtained in plastic tubes and urine volume was determined by weighing. At the midpoint of each urine collection period, blood samples were collected from the femoral artery for measurement of hematocrit and $\mathrm{PAH}$, inulin, and sodium concentrations. At the end of the experiment the kidney was removed, decapsulated, squeezed to remove blood and urine, and weighed.

Analysis. Sodium concentrations in urine and plasma were measured by flame photometry (Instrumentation Laboratory, Inc., Lexington, MA). PAH was measured by the method of Bratton and Marshall (18), and inulin by the macroanthrone method of Führ et al. (19).

Preparation of perfusate and bath solutions. In the sham-24 h, UNX-24 h, UO-24 h, and UP-24 h groups, artificial perfusate and bath solutions were used in perfusion experiments involving both control and experimental tubules. The composition of perfusate solution (in millimoles per liter) was: $\mathrm{NaCl}, 114 ; \mathrm{NaHCO}_{3}, 25 ; \mathrm{MgSO}_{4}, 1.2$ $\mathrm{K}_{2} \mathrm{HPO}_{4}, 2.5 ; \mathrm{Na}_{3}$ citrate, 1.0; sodium lactate, 4.0; $\mathrm{CaCl}_{2}$, 2.0; glucose, $5.5 ; l$-alanine, 6.0 . The composition of the bath solution was identical, except that it contained $6.0 \mathrm{~g} / 100 \mathrm{ml}$ defatted bovine serum albumin (Sigma Chemical Co., St. Louis, MO), $3 \mathrm{mmol} /$ liter $\mathrm{CaCl}_{2}$, and sufficient $1 \mathrm{M} \mathrm{NaCl}$ to match the final osmolality of the perfusate (mean, 295 mosmol). Both solutions were bubbled with $95 \% \mathrm{O}_{2} / 5 \% \mathrm{CO}_{2}$ for 25-30 min before use, and $\mathrm{pH}$ was adjusted to 7.40. For any given pair of $C$ and EXP perfusion experiments, the same batches of bath and perfusion solutions were employed, and the solutions were stored at $4^{\circ} \mathrm{C}$ during the $24-\mathrm{h}$ period between observations.

In İater experiments involving sham-7 d, UNX-7 d, UO$7 \mathrm{~d}, \mathrm{MP}-5 \mathrm{~d}$, and MP-control-5 d groups, normal rabbit serum (M.A. Bioproducts) was used as bath solution instead of artificial bath, because available supplies of defatted albumin resulted in tubule cell vacuolization and degeneration, with unstable and near-zero values for $J v$. In these experiments, tubules were perfused with serum ultrafiltrate, prepared by the use of Amicon CF 25 ultrafiltration membrane cones (Amicon Corp., Lexington, MA), with serum centrifuged at the rate of $1,500 \mathrm{rpm}$ for $15 \mathrm{~min}$ at $4^{\circ} \mathrm{C}$. After bubbling, the $\mathrm{pH}$ was adjusted to 7.4 and osmolality to $300 \mathrm{mosmol}$. The same batches of serum and ultrafiltrate were used for any given pair of control and experimental observations. Solutions were stored at minus $20^{\circ} \mathrm{C}$ during the 5- or 7-d period between study of $\mathrm{C}$ and EXP, and the osmolality was rechecked after thawing.

In vitro tubule perfusion. For tubule dissection, the renal biopsy or tissue slice was transferred to a bath of chilled artificial perfusion solution bubbled with $95 \% \mathrm{O}_{2} / 5 \% \mathrm{CO}_{2}$. To ensure that all tubules were obtained from the same anatomic region of the kidneys, i.e., the intersection of the longitudinal and transverse axes, PST were dissected from the midportion of biopsy or tissue slice specimens. Tubule bundles were grasped at the corticomedullary junction with fine forceps, and pulled in the direction of the outer cortex; individual PST were teased free from these bundles. Only superficial PST that joined PCT in the outermost $0.5 \mathrm{~mm}$ of cortex were used in these studies. When possible, the length of the experimental tubule was adjusted by trimming the distal end of the tubule, so as to match the length of its paired control tubule. Tubule lengths ranged from 1.15 to $3.5 \mathrm{~mm}$.

Each tubule was transferred to a $38^{\circ} \mathrm{C}$ thermostatically controlled bath containing $1.4 \mathrm{ml}$ of artificial bath solution or rabbit serum that was bubbled continuously with $95 \% \mathrm{O}_{2}$ / $5 \% \mathrm{CO}_{2}$ to maintain $\mathrm{pH}$ 7.40. Tubules were perfused with concentric glass pipets by the method of Burg et al. $(20,21)$, with outermost pipets containing Sylgard 184 dielectric (Dow Corning Corp., Midland, MI). ${ }^{14}$ C-Carboxy inulin (New England Nuclear, Boston, MA) was added to the perfusate $(25 \mu \mathrm{Ci} / \mathrm{ml})$ as a volume marker and FD-C No. 3 dye (Aniline and Chemical Co., Chicago, IL) was also added $(0.2$ $\mathrm{mg} / \mathrm{ml}$ ) to detect leaks or damaged cells. If more than five cells were stained with dye, the tubule was discarded. In all experiments, perfusion rate was maintained within the range of 7 to $12 \mathrm{nl} / \mathrm{min}$ by altering the height of the perfusate reservoir. After a 25-30-min period of equilibration, four to five consecutive collections of tubule fluid were made under mineral oil into a constriction pipette that was calibrated before the experiment. Samples of collected fluid were transferred into scintillation vials containing $3 \mathrm{ml} 0.1$ $\mathrm{M}$ acetic acid and $7 \mathrm{ml}$ Aquasol liquid scintillation fluid (New England Nuclear), and were counted in a Tri-Carb liquid scintillation spectrometer (Packard Instrument Co., Inc. Downers Grove, IL) to determine ${ }^{14} \mathrm{C}$ activity. $J v$ was calculated as follows $(21): J v=\left[\left(C_{i}^{\circ} / C_{0}^{\circ}\right)-1\right] V_{i} / l$, where $C_{i}^{\circ}$ and $\mathrm{C}_{0}^{\circ}$ are ${ }^{14} \mathrm{C}$ activities in the collected and perfused fluids, respectively, $V_{i}$ is the rate of tubule fluid collection, and $l$ is the tubule length. Bath solution was collected at the end of each tubule fluid collection period and the ${ }^{14} \mathrm{C}$-inulin concentration determined. If the calculated leakage rate exceeded $0.5 \%$ of the perfusion rate, the experiment was discarded. Tubule lengths were measured at the end of experiments with a calibrated reticle in the eyepiece of the microsope. Outer and inner tubule diameters (OD and ID, respectively) were measured from a photograph taken at a magnification of $\times 400$; measurements were made every 0.05 $\mathrm{mm}$ along the central portion of the tubule and mean values calculated. The inner diameter was measured as the distance between the tops of the opposing brush border membranes. Tubule cell volume (VOL) and apparent tubule serosal and 
luminal surface areas ( $A_{\mathrm{S}}$ and $A_{\mathrm{L}}$, respectively) were calculated with standard formulas for a simple thick-walled tube.

The perfusion pipette, which served as the luminal electrode, was connected to a calomel half-cell through a 0.16 $\mathrm{M} \mathrm{NaCl}-4 \%$ agar bridge. The half-cell was connected to the input of a dual electrometer (model F-233 A, W-P Instruments Inc., New Haven, CT). From the bath, the circuit was completed with a similar agar bridge connected to a reference calomel half-cell grounded through a precision millivolt reference source (model 101, W-P Instruments Inc.), which was used to calibrate the electrometer. Transepithelial electrical potential difference (PD) was nulled on the electrometer before attaching the tubule and was monitored continuously throughout each tubule perfusion experiment

Statistics. Results are presented as mean \pm SE. Statistical significance was accepted at $P<0.05$. Results for clearance studies for sham-24 h, normal, UNX-24 h, UO-24 h, and UP$24 \mathrm{~h}$ groups were compared by one-way analysis of variance (22). When significant differences were identified, Bonferroni's test (23), a version of the $t$ test appropriate for multiple comparisons, was used to identify significant differences between sham-24 h and each of the other groups. Clearance data from MP-5 and MP-control-5 d groups were compared by the unpaired $t$ test (22). In perfused tubule experiments, each EXP was compared with the $C$ from the same animal, permitting calculation of paired differences $(\Delta)$ for each parameter within each group. These paired differences were then compared, by one-way analysis of variance and Bonferroni's test as described above, among sham-24 h, UNX$24 \mathrm{~h}$, UO-24 h, and UP-24 h groups, and among sham-7 d, UNX-7 d, and UO-7 d groups. Since no control group was available for comparison with MP-5 d, EXP and C data for this group were compared directly by the paired $t$ test (22). Data organization and statistical calculations were performed on CLINFO data management and analysis system of the General Clinical Research Center, Brigham and Women's Hospital.

\section{RESULTS}

Clearance studies. The results obtained in clearance studies in sham-24 h, normal, UNX-24 h, UO-24 $\mathrm{h}$, and UP-24 h rabbits are summarized in Table $\mathrm{I}$. There were no significant differences in body weight (BW), right kidney wet weight (RtKW), Pa, or plasma sodium concentration $\left(\mathrm{P}_{\mathrm{Na}}\right)$ among these groups. Sham$24 \mathrm{~h}$ and normal did not differ significantly in values for inulin clearance $\left(C_{\mathrm{IN}}\right)$, PAH clearance $\left(C_{\mathrm{PAH}}\right)$, plasma sodium concentration $\left(\mathrm{P}_{\mathrm{Na}}\right) \times C_{\mathrm{IN}}$, urinary sodium excretion rate $\left(\mathrm{U}_{\mathrm{Na}} \mathrm{V}\right)$, whole kidney sodium reabsorption rate $\left(T_{\mathrm{Na}}\right)$, and fractional sodium excretion $\left(\mathrm{FE}_{\mathrm{Na}}\right)$, although these measures of renal function tended to be lower in sham-24 $\mathrm{h}$ animals. There were also no significant differences between sham-24 $\mathrm{h}$ and normal in values for hematocrit $(36.2 \pm 1.4$ vs. $39.5 \pm 1.3)$ or urinary sodium concentration $(97.9 \pm 16.6$ vs. $53.4 \pm 13.7 \mathrm{meq} / \mathrm{liter})$ measured at the start of clearance studies. These data indicate that the surgical preparation of the animals (i.e., flank incision and renal biopsy) did not significantly alter contralateral renal function and sodium metabolism when studied $24 \mathrm{~h}$ later.

In contrast, inulin clearance increased significantly in UNX-24 h, UO-24 h, and UP-24 h, when compared with sham-24 h, on average by 110,69 , and $64 \%$, respectively. PAH clearance also increased significantly, on average by 54 and $45 \%$ in UNX-24 h and UO-24 $\mathrm{h}$ groups, respectively, compared with sham- $24 \mathrm{~h}$. The $40 \%$ increase in $C_{\mathrm{PAH}}$ observed in UP-24 h did not

TABLE I

Summary of Results Obtained in Right Kidney Clearance Studies 24 h after Left Kidney Manipulation

\begin{tabular}{|c|c|c|c|c|c|c|c|c|c|c|c|}
\hline Study & $\begin{array}{c}\text { No. of } \\
\text { animals }\end{array}$ & BW & RtKW & $\mathrm{Pa}$ & $C_{\mathrm{IN}}$ & $C_{\mathrm{PAH}}{ }^{\bullet}$ & $\mathbf{P}_{\mathrm{Ne}_{\mathbf{0}}}$ & $\mathbf{P}_{\mathrm{N}_{0}} \times C_{\mathrm{IN}}$ & $\mathrm{U}_{\mathrm{Ne}} \mathrm{V}$ & $T_{\mathrm{Ne}}$ & $\mathrm{Fe}_{\mathrm{Ne}} \times 100$ \\
\hline & & kg & $g$ & $m m H g$ & $\mathrm{ml} / \mathrm{min}$ & $\mathrm{ml} / \mathrm{min}$ & meq/liter & $\mu e q / \min$ & $\mu e q / \min$ & $\mu e q / \min$ & $\%$ \\
\hline \multirow{2}{*}{ Sham-24 h } & 7 & 1.70 & 6.31 & 88.1 & 2.45 & 14.4 & 139.7 & 342 & 1.90 & 340 & 0.56 \\
\hline & & \pm 0.07 & \pm 0.38 & \pm 3.6 & \pm 0.19 & \pm 0.9 & \pm 1.2 & \pm 24 & \pm 0.63 & \pm 24 & \pm 0.20 \\
\hline \multirow[t]{2}{*}{ Normal } & 6 & 1.81 & 6.20 & 88.2 & 3.20 & 15.1 & 141.4 & 454 & 3.15 & 450 & 0.67 \\
\hline & & \pm 0.13 & \pm 0.30 & \pm 1.3 & \pm 0.24 & \pm 0.7 & \pm 2.7 & \pm 39 & \pm 1.06 & \pm 38 & \pm 0.23 \\
\hline \multirow[t]{2}{*}{ UNX-24 h } & 7 & 1.75 & 6.67 & 92.3 & $5.14 !$ & $22.2 \downarrow$ & 138.8 & $712 \ddagger$ & 4.87 & $707 \downarrow$ & 0.72 \\
\hline & & \pm 0.13 & \pm 0.40 & \pm 2.9 & \pm 0.50 & \pm 2.9 & \pm 0.7 & \pm 68 & \pm 0.62 & \pm 68 & \pm 0.10 \\
\hline \multirow[t]{2}{*}{ UO-24 h } & 9 & 1.88 & 7.44 & 90.1 & $4.14 t$ & $20.9 \S$ & 138.4 & $586 \ddagger$ & 4.68 & $581 t$ & 0.84 \\
\hline & & \pm 0.11 & \pm 0.39 & \pm 3.5 & \pm 0.43 & \pm 1.5 & \pm 1.0 & \pm 60 & \pm 1.32 & \pm 66 & \pm 0.22 \\
\hline \multirow[t]{2}{*}{ UP-24 h } & 8 & 1.75 & 6.55 & 93.9 & $4.02 \S$ & 20.3 & 139.0 & $557 \S$ & 3.01 & $554 \S$ & 0.54 \\
\hline & & \pm 0.12 & \pm 0.30 & \pm 2.9 & \pm 0.25 & \pm 1.3 & \pm 1.1 & \pm 33 & \pm 0.94 & \pm 33 & \pm 0.18 \\
\hline
\end{tabular}

All data $\pm \mathrm{SE}$.

- For $C_{\mathrm{PAH}}$ : UNX-24 h, $n=6$; UO-24 h, $n=8$; UP-24 h, $n=6$. For $\mathrm{U}_{\mathrm{Na}} \mathrm{V}: \mathrm{UO}-24 \mathrm{~h}, n=8$.

$\ddagger P<0.01$ vs. sham-24 h.

$\S P<0.05$ vs. sham $-24 \mathrm{~h}$. 
TABLE II

Summary of Results Obtained in Right Kidney Clearance Studies After MP-5 d

\begin{tabular}{|c|c|c|c|c|c|c|c|c|c|c|c|}
\hline & $\begin{array}{l}\text { No. of } \\
\text { animals }\end{array}$ & BW & RiKW & $\mathrm{Pa}$ & $C_{\mathrm{IN}}$ & $C_{P A H}$ & $\mathbf{P}_{\mathrm{Ne}_{\mathrm{t}}}$ & $\mathrm{P}_{\mathrm{Ne}_{\mathrm{e}}} \times C_{\mathrm{iN}}$ & $U_{N_{0}} \mathrm{~V}$ & $T_{N_{0}}$ & $\mathrm{FE}_{\mathrm{Ne}_{\mathrm{t}} \times 100}$ \\
\hline & & $\mathrm{kg}$ & $g$ & $\mathrm{mmHg}_{\mathrm{g}}$ & $\mathrm{ml} / \mathrm{min}$ & $m l / \min$ & meq/liter & meq/min & $\mu e q / \min$ & $\operatorname{\mu eq} / \min$ & $\%$ \\
\hline MP-5 d & 5 & $\begin{array}{r}1.77 \\
\pm 0.11\end{array}$ & $\begin{array}{r}8.20 \\
\pm 0.55\end{array}$ & $\begin{array}{l}95.4^{\circ} \\
\pm 4.5^{\circ}\end{array}$ & $\begin{array}{c}5.03 \downarrow \\
\pm 0.47\end{array}$ & $\begin{array}{l}22.7 \ddagger \\
\pm 1.5\end{array}$ & $\begin{array}{r}144.1 \\
\pm 2.9\end{array}$ & $\begin{array}{l}725 ! \\
\pm 70\end{array}$ & $\begin{array}{r}6.28^{\circ} \\
\pm 1.80\end{array}$ & $\begin{array}{c}719 \ddagger \\
\pm 69\end{array}$ & $\begin{array}{c}0.84^{\circ} \\
\pm 0.21\end{array}$ \\
\hline MP-control-5 d & 5 & $\begin{array}{r}1.74 \\
\pm 0.13\end{array}$ & $\begin{array}{r}6.90 \\
\pm 0.43\end{array}$ & $\begin{array}{r}81.2 \\
\pm 1.4\end{array}$ & $\begin{array}{r}2.91 \\
\pm 0.27\end{array}$ & $\begin{array}{r}13.9 \\
\pm 1.1\end{array}$ & $\begin{array}{r}138.1 \\
\pm 2.0\end{array}$ & $\begin{array}{r}401 \\
\pm 36\end{array}$ & $\begin{array}{r}0.56 \\
\pm 0.16\end{array}$ & $\begin{array}{r}401 \\
\pm 36\end{array}$ & $\begin{array}{r}0.14 \\
\pm 0.04\end{array}$ \\
\hline
\end{tabular}

All data \pm SE.

$-P<0.05$ vs. MP-control- $5 \mathrm{~d}$ by unpaired $t$ test.

$\ddagger P<0.01$ vs. MP-control- $5 \mathrm{~d}$ by unpaired $t$ test.

achieve statistical significance $(P=0.08)$. The increases in $C_{\mathrm{PAH}}$ were proportionately less than the concomitant increase in $C_{\mathrm{IN}}$, indicating a general tendency for whole kidney filtration fraction to rise in each group. This increase achieved statistical significance in UNX-24 h.

Because GFR rose in UNX-24 h, UO-24 h, and UP$24 \mathrm{~h}$ animals without a change in $\mathrm{P}_{\mathrm{Na}}$, the filtered load of sodium $\left(\mathrm{P}_{\mathrm{Na}} \times C_{\mathrm{IN}}\right)$ was significantly higher in these groups than in sham-24 h animals (Table I). No significant differences in $\mathrm{FE}_{\mathrm{Na}}$ or $\mathrm{U}_{\mathrm{Na}} \mathrm{V}$ were seen at 24 h. Hence, $T_{\mathrm{Na}}$ rose significantly in UNX-24 h, UO-24 $h$, and UP-24 h groups, averaging 107, 70, and $62 \%$ above values for sham-24 $\mathrm{h}$ animals (Table I).

Comparison of MP-5 d and MP-control-5 d groups (Table II) showed no significant differences in BW or RtKW. Values for $\overline{\mathrm{P}}$ a were significantly higher in MP$5 \mathrm{~d}$ than in MP-control-5 d (95.4 \pm 4.5 vs. $81.2 \pm 1.4$ $\mathrm{mmHg}$ ), and $C_{\mathrm{IN}}$ and $C_{\mathrm{PAH}}$ were also significantly increased, averaging 73 and $63 \%$, respectively, above MP-control-5 d values (Table II). In MP-5 d rabbits, values for $P_{\mathrm{Na}}$ were not different from those in MP. control-5 $\mathrm{d}$ animals, whereas values for filtered load of sodium, $\mathrm{U}_{\mathrm{Na}} \mathrm{V}, \mathrm{FE}_{\mathrm{Na}}$, and $T_{\mathrm{Na}}$ were significantly higher (Table II).

Perfusion studies. To minimize animal-to-animal variations in $J v$ values in PST segments, we assessed the effect of each experimental maneuver by comparing the $J v$ value obtained in each EXP with results from the paired $\mathrm{C}$ derived from the same animal. The validity of this approach was corfirmed statistically by demonstrating a significant $(P<0.05)$ correlation (by linear regression analysis) between $C$ and EXP values for $J v$ within every group. Similarly, in sham-24 h, significant correlations were established between EXP and $C$ for tubule length, perfusion rate, OD, ID, and $P D$. These correlations indicate that pairing for these variables is both reasonable and necessary on statistical grounds to account appropriately for an important portion of the variance in the data (23). Because other tubule parameters used in this study were derived from these primary data (i.e., cell volume, cell surface area), they were also evaluated by paired comparisons.

Jv measurements. As shown in Tables III and IV, the surgical preparation used in this protocol did not influence $J v$. In both sham-24 $h$ and sham-7 d groups,

TABLE III

Summary of Results Obtained in PST In Vitro Perfusion Studies (24 h)

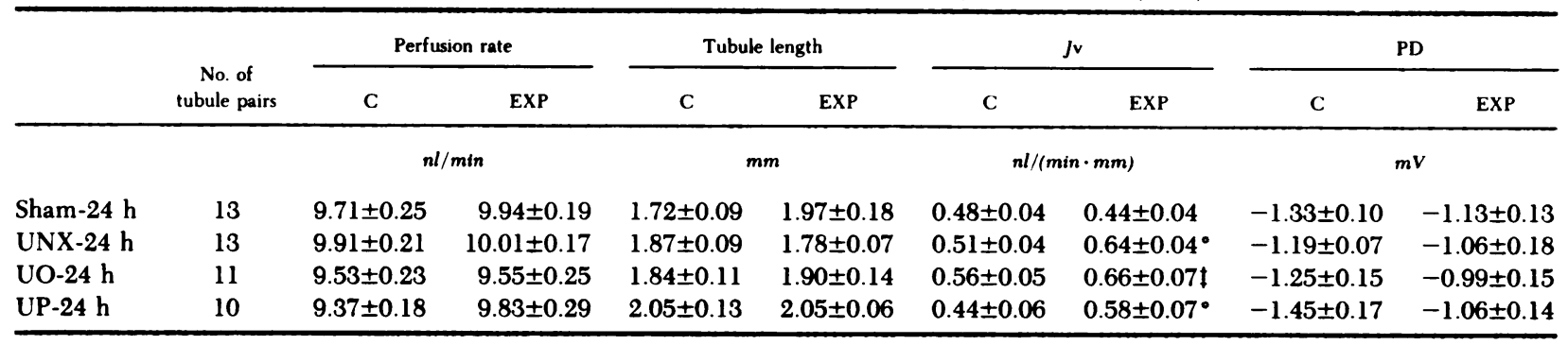

All data $\pm S E$.

- $P<0.01$ for (EXP-C) vs. sham-24 h (EXP-C) for each parameter.

$\downarrow P<0.05$ for (EXP-C) vs. sham-24 h (EXP-C) for each parameter. 
TABLE IV

Summary of Results Obtained in PST In Vitro Perfusion Studies (5-7 d)

\begin{tabular}{|c|c|c|c|c|c|c|c|c|c|}
\hline & \multirow{2}{*}{$\begin{array}{l}\text { No. of } \\
\text { tubule pairs }\end{array}$} & \multicolumn{2}{|c|}{ Perfusion rate } & \multicolumn{2}{|c|}{ Tubule length } & \multicolumn{2}{|c|}{$J v$} & \multicolumn{2}{|c|}{ PD } \\
\hline & & C & EXP & C & EXP & $\mathrm{C}$ & EXP & C & EXP \\
\hline & & \multicolumn{2}{|c|}{$n l / m i n$} & \multicolumn{2}{|c|}{$m m$} & \multicolumn{2}{|c|}{$n l /(\min \cdot m m)$} & \multicolumn{2}{|c|}{$m V$} \\
\hline Sham-7 d & 6 & $9.40 \pm 0.29$ & $9.54 \pm 0.15$ & $2.22 \pm 0.17$ & $2.28 \pm 0.18$ & $0.46 \pm 0.05$ & $0.42 \pm 0.04$ & $-1.53 \pm 0.22$ & $-1.50 \pm 0.12$ \\
\hline UNX-7 d & 6 & $9.36 \pm 0.23$ & $9.87 \pm 0.25$ & $2.11 \pm 0.19$ & $2.58 \pm 0.27$ & $0.44 \pm 0.04$ & $0.62 \pm 0.06^{\circ}$ & $-1.40 \pm 0.13$ & $-1.32 \pm 0.20$ \\
\hline UO-7 d & 6 & $9.57 \pm 0.18$ & $9.53 \pm 0.27$ & $2.01 \pm 0.21$ & $2.28 \pm 0.11$ & $0.44 \pm 0.06$ & $0.55 \pm 0.05^{\circ}$ & $-1.55 \pm 0.24$ & $-1.48 \pm 0.11$ \\
\hline MP-5 d & 10 & $9.83 \pm 0.30$ & $10.13 \pm 0.16$ & $1.83 \pm 0.13$ & $2.17 \pm 0.11$ & $0.58 \pm 0.06$ & $0.74 \pm 0.05 \ddagger$ & $-1.26 \pm 0.13$ & $-1.07 \pm 0.10$ \\
\hline
\end{tabular}

All data $\pm \mathrm{SE}$.

- $P<0.01$ for (EXP-C) vs. sham-7 d (EXP-C) for each parameter.

$\downarrow P<0.01$ vs. control tubule by paired $t$ test.

the paired differences for $J v$ between $C$ and EXP $(\Delta J v)$ did not differ significantly from zero [sham-24 h: $\Delta J \mathrm{v}=-0.04 \pm 0.03 \mathrm{nl} /(\mathrm{min} \cdot \mathrm{mm}) ;$ sham-7 d: $\Delta J \mathrm{v}$ $=-0.03 \pm 0.02 \mathrm{nl} /(\mathrm{min} \cdot \mathrm{mm})]$. In contrast, $\Delta J \mathrm{v}$ observed at $24 \mathrm{~h}$ after UNX, UO, and UP were each significantly different from $\Delta J v$ in sham-24 h (Table III). The absolute and percentage increases in $J v$ were: UNX-24 h, $0.13 \pm 0.03 \mathrm{nl} /(\mathrm{min} \cdot \mathrm{mm}), 29 \pm 8 \%, P<0.01$ for each; UO-24 h, $0.10 \pm 0.04 \mathrm{nl} /(\mathrm{min} \cdot \mathrm{mm}), 19 \pm 8 \%$, $P<0.05$; UP-24 h, $0.13 \pm 0.04 \mathrm{nl} /(\mathrm{min} \cdot \mathrm{mm}), 31 \pm 8 \%$, $P<0.01$. Thus, by performing paired measurements in the same animal, we were able to detect modest but significant increases in $J v$ only $24 \mathrm{~h}$ after three different maneuvers that caused abolition of contralateral renal excretory function.
The early increases in Jv seen in UNX and UO experiments also persisted at $7 \mathrm{~d}$ (Table IV). Thus, in $\mathrm{UNX}-7 \mathrm{~d}, J \mathrm{v}$ rose by $0.18 \pm 0.04 \mathrm{nl} /(\mathrm{min} \cdot \mathrm{mm})$ or $48 \pm 11 \%$ over base-line values $(P<0.01)$. Similarly, in UO-7d, $J \mathrm{v}$ increased by $0.11 \pm 0.04 \mathrm{nl} /(\mathrm{min} \cdot \mathrm{mm})$ or $29 \pm 11 \%(P<0.01)$. As shown in Table IV, chronic administration of MP (MP-5 d) also caused a significant augmentation of fluid reabsorption rate over baseline values, as $J v$ increased by $0.16 \pm 0.05 \mathrm{nl} /(\mathrm{min}$. $\mathrm{mm}$ ), or $37 \pm 11 \%$ ( $P<0.01$ by paired $t$ test $)$.

The changes in $J v$ values observed in UNX, UO, UP, and MP groups at $24 \mathrm{~h}, 5 \mathrm{~d}$, and $7 \mathrm{~d}$ were not attributable to differences between control and experimental tubules in such quantities as perfusion rate, tubule length, or potential difference (Tables III, IV) since no

TABLE V

Relationship of Jv to Indices of PST Hypertrophy (24 h)

\begin{tabular}{|c|c|c|c|c|c|c|c|c|c|}
\hline & \multirow{2}{*}{$\begin{array}{c}\text { No. of } \\
\text { tubule pairs }\end{array}$} & \multicolumn{2}{|c|}{ ID } & \multicolumn{2}{|c|}{ OD } & \multicolumn{2}{|c|}{ VOL } & \multicolumn{2}{|c|}{$A_{s}$} \\
\hline & & c & EXP & C & EXP & C & EXP & C & EXP \\
\hline & & \multicolumn{2}{|c|}{$\mu m$} & \multicolumn{2}{|c|}{$\mu m$} & \multicolumn{2}{|c|}{$\times 10^{-4} \mathrm{~mm} / \mathrm{mm}$} & \multicolumn{2}{|c|}{$\times 10^{-8} \mathrm{~mm}^{2} / \mathrm{mm}$} \\
\hline Sham-24 h & 12 & $23.6 \pm 0.9$ & $24.5 \pm 1.3$ & $46.4 \pm 1.1$ & $46.8 \pm 1.3$ & $12.6 \pm 0.7$ & $12.5 \pm 0.7$ & $14.6 \pm 0.3$ & $14.7 \pm 0.4$ \\
\hline UNX-24 h & 13 & $23.9 \pm 1.3$ & $23.4 \pm 0.9$ & $46.2 \pm 1.0$ & $45.4 \pm 0.8$ & $12.2 \pm 0.7$ & $11.9 \pm 0.6$ & $14.5 \pm 0.3$ & $14.3 \pm 0.2$ \\
\hline UO-24 h & 10 & $23.1 \pm 1.3$ & $22.1 \pm 1.1$ & $44.6 \pm 1.1$ & $44.3 \pm 1.4$ & $11.4 \pm 0.7$ & $11.6 \pm 0.8$ & $14.0 \pm 0.3$ & $13.9 \pm 0.4$ \\
\hline UP-24 h & 7 & $22.3 \pm 0.8$ & $23.2 \pm 0.2$ & $45.7 \pm 1.5$ & $46.3 \pm 1.1$ & $12.6 \pm 1.0$ & $12.6 \pm 0.8$ & $14.4 \pm 0.5$ & $14.5 \pm 0.4$ \\
\hline
\end{tabular}

All data \pm SE.

- $P<0.01$ for (EXP-C) vs. sham-24 h (EXP-C) for each parameter I $P<0.05$ for (EXP-C) vs. sham-24 h (EXP-C) for each parameter. $\S P<0.07$ for $($ EXP-C) vs. sham-24 h (EXP-C) for each parameter. 
significant changes in these parameters were found between control and experimental tubules in any group. Although comparison of $\Delta J v$ results between $24 \mathrm{~h}$ and $7 \mathrm{~d}$ groups may not be strictly appropriate, because different types of bath and perfusate solutions were used, no significant differences were evident in values for $\Delta J v$ between UNX-24 h and UNX-7 d, or between UO-24 $\mathrm{h}$ and UO-7 $\mathrm{d}$.

Relationship of Jv to tubule hypertrophy. As shown in Tables I and II, no significant increase was noted in RtKW at $24 \mathrm{~h}$ after UNX, UO, or UP, nor at $5 \mathrm{~d}$ in the MP-5 d group. However, the possibility existed that more subtle hypertrophic changes could account for observed increases in Jv. To assess whether increases in tubule volume or surface area paralleled the rise in fluid reabsorption rate seen after UNX, UO, UP, and MP, we used mean ID and OD to calculate VOL, $A_{\mathrm{L}}$, and $A_{\mathrm{S}}$, on the assumption that these surfaces could be represented by simple cylinders. Results of these measurements and calculations are shown in Tables V and VI. (Because photographs adequate for measurements of ID and OD were not obtained in all tubules in which $J v$ was measured, fewer tubule pairs are included in these analyses than were used for measurement of $J \mathbf{v}$ ).

No differences in values for control tubule OD, ID, VOL, $A_{\mathrm{L}}$, and $A_{\mathrm{S}}$ were found when sham-24 h, UNX$24 \mathrm{~h}, \mathrm{UO}-24 \mathrm{~h}$, and UP-24 h groups were compared (Table V). Furthermore, no significant changes in these parameters were seen in paired comparisons of control and experimental tubules from each of these groups (Table V). These findings indicate that tubule hypertrophy is not evident at this early period after loss of contralateral renal excretory function, even though significant increases in $\mathrm{Jv}$ were demonstrable concomitantly. To evaluate this impression further, we normalized $J v$ for $A_{L}$ and $A_{S}$ and for VOL, rather than for tubule length, deriving values for $J_{v} / A_{L}, J v / A_{S}$, and $J v / V O L$. As shown in Table $V$, significant increases in fluid reabsorption rate were still apparent in UNX-24 h, UO-24 h, and UP-24 h groups, although $\Delta(\mathrm{Jv} / \mathrm{VOl})$ for UO-24 $\mathrm{h}$ was of borderline significance $(P<0.07)$. These results support the interpretation that the early rise in $J v$ observed in these groups was independent of tubule hypertrophy, as reflected by changes in VOL, $A_{\mathrm{s}}$, or $A_{\mathrm{L}}$.

In contrast to the results at $24 \mathrm{~h}$, evidence for PST hypertrophy was obtained in UNX and UO groups studied at $7 \mathrm{~d}$, and in the MP-5 d group as well (Table VI). Whereas sham-24 $\mathrm{h}$ tubules showed no change in ID, OD, or calculated values for VOL, $A_{S}$, or $A_{L}$, a significant rise in OD was found in UNX-7 d, leading to significant increases in calculated values for VOL and $A_{s}$. In UO-7 d, small decreases in ID and increases in OD yielded a modest but statistically insignificant rise in VOL (Table VI). Nevertheless, although $J v$ rose significantly in both UNX-7 $\mathrm{d}$ and UO-7 d, when $J v$ was normalized for VOL the resulting changes $[\Delta(J v)$ VOL)] were no longer significantly different $(P>0.10)$ from sham-7 d, indicating that in UNX-7 d and UO$7 \mathrm{~d}, \mathrm{Jv}$ and VOL rose proportionately. In contrast, normalization of $J v$ for $A_{S}$ or $A_{L}$ did not obviate the rise in $J v$ in either group, since in both UNX-7 d and UO-7 d, $\Delta\left(J v / A_{S}\right)$ and $\Delta\left(J v / A_{L}\right)$ rose significantly. Thus, increases in $A_{\mathrm{L}}$ or $A_{\mathrm{S}}$ did not parallel the concomitant rise in $\mathrm{Jv}$ evident at $7 \mathrm{~d}$.

TABLE V, continued.

\begin{tabular}{|c|c|c|c|c|c|c|c|c|c|}
\hline C & EXP & C & EXP & C & EXP & C & EXP & C & EXP \\
\hline \multicolumn{2}{|c|}{$\times 10^{-2} \mathrm{~mm}^{2} / \mathrm{mm}$} & \multicolumn{2}{|c|}{$n l /(\min \cdot m m)$} & \multicolumn{2}{|c|}{$\times 10^{2} \mathrm{nl} /\left(\min \cdot \mathrm{mm}^{\mathrm{s}}\right)$} & \multicolumn{2}{|c|}{$n l /\left(\min \cdot m m^{2}\right)$} & \multicolumn{2}{|c|}{$n l /\left(\min \cdot m m^{2}\right)$} \\
\hline \multicolumn{10}{|c|}{$(n=13)$} \\
\hline $7.01 \pm 0.24$ & $7.29 \pm 0.62$ & $\begin{array}{r}\langle n \\
0.44 \pm 0.06 \\
(n\end{array}$ & $\begin{aligned}= & 11) \\
& 0.58 \pm 0.07^{\circ} \\
= & 10)\end{aligned}$ & $3.66 \pm 0.52$ & $5.09 \pm 0.73^{\circ}$ & $3.17 \pm 0.47$ & $4.35 \pm 0.60^{\circ}$ & $6.56 \pm 1.02$ & $8.69 \pm 1.24^{\circ}$ \\
\hline
\end{tabular}


TABLE VI

Relationship of Jv to Indices of PST Hypertrophy (5-7 d)

\begin{tabular}{|c|c|c|c|c|c|c|c|c|c|}
\hline & \multirow{2}{*}{$\begin{array}{l}\text { No. of } \\
\text { tubule pairs }\end{array}$} & \multicolumn{2}{|c|}{ ID } & \multicolumn{2}{|c|}{ OD } & \multicolumn{2}{|c|}{ VOL } & \multicolumn{2}{|c|}{$A_{s}$} \\
\hline & & C & EXP & C & EXP & C & EXP & C & EXP \\
\hline & & \multicolumn{2}{|c|}{$\mu m$} & \multicolumn{2}{|c|}{$\mu m$} & \multicolumn{2}{|c|}{$\times 10^{-4} \mathrm{~mm}^{\mathrm{s}} / \mathrm{mm}$} & \multicolumn{2}{|c|}{$\times 10^{-8} \mathrm{~mm}^{2} / \mathrm{mm}$} \\
\hline Sham-7d & 6 & $22.7 \pm 1.0$ & $21.8 \pm 1.3$ & $47.8 \pm 1.8$ & $48.4 \pm 1.7$ & $13.9 \pm 1.1$ & $14.7 \pm 0.9$ & $15.0 \pm 0.6$ & $15.2 \pm 0.5$ \\
\hline UNX-7 d & 6 & $22.9 \pm 1.0$ & $25.4 \pm 1.7$ & $48.8 \pm 2.2$ & $54.6 \pm 2.0^{\circ}$ & $14.7 \pm 1.4$ & $18.3 \pm 1.3 \ddagger$ & $15.3 \pm 0.7$ & $17.1 \pm 0.6^{\circ}$ \\
\hline UO-7 d & 6 & $24.8 \pm 1.4$ & $21.6 \pm 1.1$ & $48.5 \pm 1.3$ & $49.6 \pm 1.2$ & $13.6 \pm 0.5$ & $15.6 \pm 0.9$ & $15.2 \pm 0.4$ & $15.6 \pm 0.4$ \\
\hline MP-5 d & 10 & $23.0 \pm 1.2$ & $24.1 \pm 0.7$ & $44.5 \pm 1.3$ & $47.5 \pm 1.0 \S$ & $11.4 \pm 0.7$ & $13.2 \pm 0.5 \S$ & $14.0 \pm 0.4$ & $14.9 \pm 0.3 \S$ \\
\hline
\end{tabular}

All data \pm SE.

- $P<0.01$ for (EXP-C) vs. sham-7 d (EXP-C).

$\ddagger P<0.05$ for (EXP-C) vs. sham-7 d (EXP-C).

$\S P<0.01$ vs. $C$ by paired $t$ test.

" $P<0.05$ vs. C by paired $t$ test.

A similar pattern of results was seen with MP-5 d animals (Table VI). After chronic MP administration, $O D, V O L$, and $A_{s}$ rose significantly, but a significant increase in $J v$ was still apparent in the MP group when $J v$ was normalized for luminal or serosal surface area. However, no significant increase was seen after chronic MP administration when $J v$ was related to cell volume. Thus, as seen with UNX-7 d and UO-7 d, the increase in $\mathrm{Jv}$ that follows MP administration is proportional to the rise in cell volume, but can be dissociated from other measures of tubule hypertrophy.

\section{DISCUSSION}

It is well established that the chronic reductions in renal mass and excretory function induced by UNX initiate compensatory increases in the function and size of the remaining kidney $(1,24)$. The time course and magnitude of these increases remain somewhat controversial, however. In this study, we found that in volume-replete rabbits studied $24 \mathrm{~h}$ after $\mathrm{UNX}$ values for $C_{\mathrm{IN}}$ and $C_{\mathrm{PAH}}$ were 110 and $54 \%$ greater than those of sham-24 $\mathrm{h}$ animals, respectively (Table I). The magnitude of these increases is larger than previously reported by others (13), and may, in part, reflect the effect of surgery to reduce the value for these parameters in sham-24 h control group. Nevertheless, comparison of UNX-24 h and unoperated normal group still shows a $47 \%$ increase in $C_{\mathrm{PAH}}$ and a $60 \%$ increase in $C_{\mathrm{IN}}$, indicating that the rabbit kidney displays a striking capacity to compensate rapidly for the loss of renal mass and excretory function by increasing renal plasma flow rate and GFR.

Along with the increase in GFR at $24 \mathrm{~h}$ after UNX, a significant increase in $T_{\mathrm{Na}}$ was also evident. The magnitude of this change in $T_{\mathrm{Na}}$ was comparable to the rise in $C_{\mathrm{IN}}$, indicating a high degree of glomerulotubular balance at this early stage after loss of renal mass. Others have shown that the rise in $T_{\mathrm{Na}}$ after chronic subtotal ablation of renal mass is accompanied by an increase in the intrinsic transport capacity of PCT and PST segments of the remaining nephrons $(15,16)$. We reasoned that the early and large increase in $T_{\mathrm{Na}}$ resulting from UNX might be paralleled by a similar early increase in $J v$ values in PST. Our results show that such a rise in $J v$ in PST is demonstrable as early as $24 \mathrm{~h}$ after UNX, and is sustained for at least $7 \mathrm{~d}$. These data are in contrast to those of others, who did not identify a statistically significant rise in $J v$ in PST segments 1-4 mo after a slightly lesser degree of reduction in renal mass (15). A greater degree of renal ablation, on the other hand, induced a large $(70 \%)$ increase in Jv in PST. Similarly, in PCT, the increase in $J v$ after uninephrectomy is not consistently significant $(16,25)$ whereas a significant rise is seen after chronic subtotal ablation (16). These results suggest that either the small difference in the degree of ablation or the greater sensitivity of our paired-tubule analysis accounts for the apparent discrepancy between those data and ours.

In view of the foregoing evidence that both whole kidney and local PST functions respond quickly to removal of the contralateral kidney, we next investigated whether these changes were a consequence either of the loss of metabolically active renal tissue or of a reduction in renal excretory function. To assess this question, we utilized UO and UP, maneuvers which halved renal excretory function without removing renal mass. We found that at $24 \mathrm{~h}$, UO and UP produced significant increases in contralateral kidney $C_{\mathrm{PAH}}, C_{\mathrm{IN}}$, and $T_{\mathrm{Na}}$ compared with sham-24 h, although the magnitude of these increases was smaller than those seen with UNX-24 h. Although other interpretations are possible, these data are consistent with the view that retention of one or more urinary solutes, through some direct or indirect effects, pro- 
TABLE VI, continued.

\begin{tabular}{|c|c|c|c|c|c|c|c|c|c|}
\hline \multicolumn{2}{|c|}{$A_{\mathbf{L}}$} & \multicolumn{2}{|c|}{$J v$} & \multicolumn{2}{|c|}{ Jv/VOL } & \multicolumn{2}{|c|}{$J v / A_{s}$} & \multicolumn{2}{|c|}{$J \mathbf{v} / A_{L}$} \\
\hline C & EXP & C & EXP & C & EXP & C & EXP & C & EXP \\
\hline \multicolumn{2}{|c|}{$\times 10^{-2} \mathrm{~mm}^{2} / \mathrm{mm}$} & \multicolumn{2}{|c|}{$n l /(m i n \cdot m m)$} & \multicolumn{2}{|c|}{$\times 10^{2} \mathrm{nl} /\left(\min \cdot \mathrm{mm}^{\mathrm{s}}\right)$} & \multicolumn{2}{|c|}{$n l /\left(\min \cdot m m^{2}\right)$} & \multicolumn{2}{|c|}{$n l /\left(\min \cdot m m^{2}\right)$} \\
\hline $7.14 \pm 0.31$ & $6.84 \pm 0.42$ & $0.46 \pm 0.05$ & $0.42 \pm 0.04$ & $3.38 \pm 0.39$ & $2.98 \pm 0.42$ & $3.06 \pm 0.31$ & $2.82 \pm 0.32$ & $6.45 \pm 0.65$ & $6.30 \pm 0.68$ \\
\hline $7.18 \pm 0.32$ & $7.99 \pm 0.54$ & $0.44 \pm 0.04$ & $0.62 \pm 0.06^{\bullet}$ & $3.13 \pm 0.41$ & $3.47 \pm 0.43$ & $2.88 \pm 0.29$ & $3.62 \pm 0.34^{\circ}$ & $6.12 \pm 0.55$ & $7.79 \pm 0.65$ \\
\hline $7.78 \pm 0.44$ & $6.78 \pm 0.35$ & $0.44 \pm 0.06$ & $0.55 \pm 0.05^{\circ}$ & $3.24 \pm 0.40$ & $3.54 \pm 0.34$ & $2.91 \pm 0.39$ & $3.52 \pm 0.32^{\circ}$ & $5.80 \pm 0.89$ & $8.14 \pm 0.72^{\circ}$ \\
\hline $7.21 \pm 0.38$ & $7.57 \pm 0.24$ & $0.58 \pm 0.06$ & $0.74 \pm 0.05 \$$ & $5.11 \pm 0.43$ & $5.67 \pm 0.36$ & $4.14 \pm 0.40$ & $4.97 \pm 0.29^{\prime \prime}$ & $8.32 \pm 1.06$ & $9.82 \pm 0.56^{\prime \prime}$ \\
\hline
\end{tabular}

duces the observed changes in renal function (26). The relatively greater increases in $C_{\mathrm{PAH}}$ and $C_{\mathrm{IN}}$ in the UNX group compared with the UO and UP groups might be accounted for by an early and rapid accumulation of unexcreted solutes in plasma after UNX, in contrast to the UO and UP groups, in which urine may continue to accumulate in the obstructed urinary collecting system or in the peritoneal space for some minutes to hours before being reabsorbed into the plasma. The greater stimulatory effect of UNX on $C_{\mathrm{PAH}}$ and $C_{\mathrm{IN}}$ may reflect an independent influence of a reduced renal mass per se on contralateral renal function (27).

The consequences of halving renal excretory function without loss of renal mass were also manifest in isolated nephron segments as well. As was found after UNX, UO and UP led to significant increases in $J v$ in PST at $24 \mathrm{~h}$, and this effect persisted for $\mathbf{7 d}$ after UO. The observed changes in $J v$ values were not related to any systematic differences in tubule length, perfusion rate, or PD (Tables III, IV). Differences between control and experimental tubules in the proportion of cortical $\left(\mathbf{S}_{2}\right)$ to medullary $\left(\mathbf{S}_{3}\right)$ PST segments might also influence the results of our $\mathrm{Jv}$ measurements, since the more superficial PST segments are known to exhibit higher values for $J v$ and lower values for PD than do more distal PST segments (28). That this form of experimental bias is unlikely is suggested by $(a)$ lack of change in $J v$ in sham-24 $\mathrm{h}$ and sham-7 d animals, $(b)$ rigorous criteria used for the selection of superficial PST $\left(S_{2}\right)$ segments, and $(c)$ absence of significant differences between control and experimental tubules of each group in values for PD despite the increase in $J v$. To negate the potential influence of surface location (i.e., kidney pole vs. midsection) on reabsorption rate, all tubules were obtained from the region at the intersection of the longitudinal and transverse axes of the kidney.

The parallel changes in GFR and Jv after UNX, UO, and UP suggest that the two are in some fashion linked. Although retention of urinary solutes may exert independent stimulatory influences on GFR and $J v$, a more parsimonious explanation is that proximal tubule $J v$ is modulated by GFR or some related dependent variable, such as filtered solute load, peritubular Starling forces, or tubule fluid flow rate $(16,28)$. To determine whether the rise in Jv observed in UNX, UO, and UP groups was related to the concomitant rise in GFR, we used MP administration, a maneuver known to increase GFR in the rat (17). Consistent with this hypothesis, concomitant augmentation of both $C_{1 N}$ and $J v$ in PST was observed in MP-5 d animals.

Further support for this interpretation is derived from a statistical analysis of the relationship between the changes in $J v$ and $C_{\mathrm{IN}}$ induced by these various maneuvers. As shown in Fig. 1, a significant correlation exists (by linear regression analysis) between $C_{\mathrm{IN}}$ and $J v$, when mean values for these parameters in sham$24 \mathrm{~h}, \mathrm{UNX}-24 \mathrm{~h}, \mathrm{UO}-24 \mathrm{~h}, \mathrm{UP}-24 \mathrm{~h}$, and MP-5 d groups are considered together (linear regression: $\Delta J v=0.062$ $\left.\times C_{\mathrm{IN}}-0.17, r=0.91, P<0.05\right)$. Thus, the prevailing level of GFR at time of study may play a central role in modulating proximal tubule $J v$ under circumstances not limited to compensatory adaptation to reduced renal mass. Consonant with this concept are the data of Knepper and Burg (28), who observed that the stimulatory effect of desoxycorticosterone acetate on PST $J v$ appeared to depend on expansion of extracellular fluid volume. GFR and renal blood flow were not measured in those studies but they very likely increased as well, a pattern consistent with our current observations.

The modest increases in Jv (19-43\%) seen after each of the experimental maneuvers used in this study were much less than the simultaneous increases in $T_{\mathrm{Na}}$. However, increases in tubule length would add to the in vivo effect of the observed changes in Jv. Although 


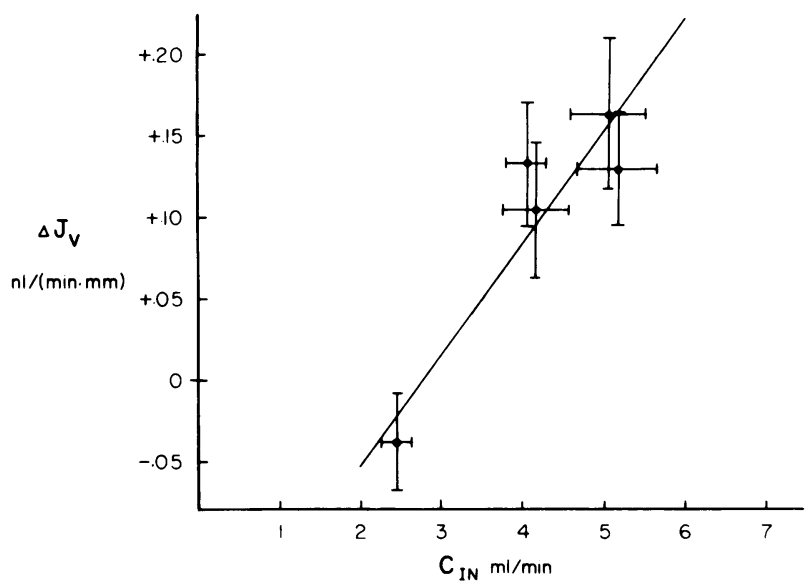

Figure 1 Effect of experimental manipulations on $C_{1 N}$ and $\Delta J v$. Results for sham-24 h, UNX-24 h, UO-24 h, UP-24 h, and MP-5 d are shown. Linear regression equation: $\Delta J v=$ $0.062 \times C_{\mathrm{IN}}-0.17, r=0.91, P<0.05$.

PST lengths were not assessed in situ in the present study, the reported $35 \%$ increase in proximal tubule length after chronic UNX in rats (2) suggests that this issue may be of relevance in assessing the relationship of $J \mathrm{v}$ to $T_{\mathrm{Na}}$. Furthermore, $T_{\mathrm{Na}}$ is regulated by many forces not operative under the in vitro conditions used for measurements of $J \mathbf{v}$. We did not directly assess the individual effects on $T_{\mathrm{Na}}$ of changes in circulating hormones, renal nerve traffic, intrarenal blood flow distribution and peritubular Starling forces that may result from UNX, UO, UP, and MP. It may be noted, however, that with each of these maneuvers whole kidney filtration fraction tended to rise, suggesting that protein oncotic pressure in peritubular capillaries was augmented, thereby altering the Starling forces which regulate proximal tubule fluid reabsorption in vivo. The contribution of other nephron segments to the overall rise in $T_{\mathrm{Na}}$ was not determined in the current study, but probably also played a role in regulating $T_{\mathrm{Na}}$ after loss of renal excretory function $(2,29)$.

Compensatory renal hypertrophy is believed to be fundamental to the long-term maintenance of body fluid homeostasis after loss of renal mass (1). Whether such hypertrophy is essential for the early functional responses to reduced renal excretory capacity is less certain. It is well established that increases in RNA (30), DNA (31), phospholipid (32), and protein synthesis (33) are evident within hours after UNX in the rat, although the actual increase in kidney dry mass at $24 \mathrm{~h}$ is only $\sim 3 \%(31,34)$. In this study, kidney wet weights were not greater than sham controls at $24 \mathrm{~h}$ after UNX, UO, or UP, even though $J v$ increased significantly. Since a role for proximal tubule hypertrophy has been proposed to account for the chronic rise in $J v$ that follows partial renal ablation $(15,16)$ or desoxycorticosterone acetate administration (28), we investigated whether lesser degrees of hypertrophy were a necessary concomitant of an early increase in $J v$. Our data suggest that the increases in Jv seen in PST segments at $24 \mathrm{~h}$ after maneuvers that halved renal excretory function do not depend upon equivalent degrees of local tubule segment hypertrophy (Tables V, VI). In contrast, the changes in Jv evident in these studies at $7 \mathrm{~d}$, and reported by others under more chronic conditions, are associated with equivalent increases in $\operatorname{VOL}(15,16)$, and smaller but significant increases in $A_{S}$ (Table VI) and $A_{\mathrm{L}}$ (16).

The conclusion that changes in $J v$ and tubule hypertrophy can be dissociated at $24 \mathrm{~h}$ depends upon the validity and sensitivity of VOL, $A_{\mathrm{S}}$, and $A_{\mathrm{L}}$ as indices of tubule hypertrophy. There are certain limitations to such methods. Although significant increases in VOL of as little as $16 \%$ (MP-5 d) were detected, use of the brush border apex to define ID results in the inclusion of the extracellular region of the microvillous intersticies as part of the apparent cell volume. In addition, since tubule dry weights were not determined, the results of VOL measurement do not differentiate between gains in cell solute and cell water. More importantly, $A_{S}$ and $A_{\mathrm{L}}$ are only crude estimates of the relevant morphologic parameters, since they do not reflect the extent of lateral cell surface interdigitations or luminal microvillous projections. Indeed, preliminary data obtained by histomorphometric analysis suggests that brush border membrane surface area does increase after chronic subtotal renal ablation (35), and our methodology is not capable of excluding these more subtle changes in luminal or basolateral cell surface area.

Nevertheless, the dissociation evident at $24 \mathrm{~h}$ between changes in $J v$ and VOL suggests that increased cell volume may not be a sine qua non for augmentation of $J v$. The process which accounts for the early increase in $J v$ may be unrelated to the later hypertrophy-associated rise in $J v$. More likely, however, is the concept that a single mechanism, independent of cell mass per se and susceptible to relatively rapid in vivo modulation, precedes the concomitant tubule hypertrophy. Whether the tubule property being influenced is membrane surface area, luminal membrane solute permeability, cell energy metabolism, membrane $\mathrm{Na}$ K-ATPase activity, hydraulic permeability, or some other parameter is not apparent from these studies, and will doubtless serve as the subject of fruitful future investigation.

\section{ACKNOWLEDGMENTS}

We wish to express our appreciation to Drs. Mark Knepper, Harry R. Jacobson, and Willet Whitmore for their helpful suggestions; to Ms. Julia Troy for technical assistance; and to Ms. Denise Voss for expert secretarial assistance. Dr. Mi- 
chael Feldstein, Biostatistics Consulting Laboratory, Harvard School of Public Health, provided advice and guidance in the data analysis.

CLINFO computing facilities were supported by a grant from the Division of Research Resources, National Institutes of Health (RR 00888). This study was supported in part by a grant from the National Institutes of Health (AM 19467).

\section{REFERENCES}

1. Hayslett, J. P. 1979. Functional adaptation to reduction in renal mass. Physiol. Rev. 59:137-164.

2. Hayslett, J. P., M. Kashgarian, and F. H. Epstein. 1968. Functional correlates of compensatory renal hypertrophy. J. Clin. Invest. 47:774-782.

3. Kaufman, J. M., H. J. Dimeola, N. J. Siegel, B. Lytton, M. Kashgarian, and J. P. Hayslett. 1974. Compensatory adaptation of structure and function following progressive renal ablation. Kidney Int. 6:10-17.

4. Katz, A. I., and F. H. Epstein. 1967. Relation of glomerular filtration rate and sodium reabsorption to kidney size in compensatory renal hypertrophy. Yale $J$. Biol. Med. 40:222-230.

5. Deen, W. M., D. A. Maddox, C. R. Robertson, and B. M. Brenner. 1974. Dynamics of glomerular ultrafiltration in the rat. VII. Response to reduced renal mass. Am. J. Physiol. 227:556-562.

6. Rous, S. N., and K. G. Wakin. 1967. Kidney function before, during and after compensatory hypertrophy. $J$. Urol. 98:30-35.

7. Pabico, R. C., B. A. McKenna, and R. B. Freeman. 1975. Renal function before and after unilateral nephrectomy in renal donors. Kidney Int. 8:166-175.

8. Schultze, R. G., H. S. Shapiro, and N. S. Bricker. 1969. Studies on the control of sodium excretion in experimental uremia. J. Clin. Invest. 48:869-877.

9. Hayslett, J. P., M. Kashgarian, and F. H. Epstein. 1969. Mechanism of change in the excretion of sodium per nephron when renal mass is reduced. J. Clin. Invest. 48:1002-1006.

10. Slatopolsky, E., I. O. Elkan, C. Weerts, and N. S. Bricker. 1968. Studies on the characteristics of the control system governing sodium excretion in uremic man. J. Clin. Invest. 47:521-530.

11. Emmanouel, D. S., M. D. Lindheimer, and A. I. Katz. 1975. Urinary concentration and dilution after unilateral nephrectomy in the rat. Clin. Sci. Mol. Med. 49:563-572.

12. Sachtjen, E., L. Rabinowitz, and P. E. Binkerd. 1977. Renal concentrating ability in the uninephrectomized rat. Am. J. Physiol. 23:F428-F437.

13. Potter, D. E., E. P. Leumann, T. Sakai, and M. A. Holliday. 1974. Early responses of glomerular filtration rate to unilateral nephrectomy. Kidney Int. 5:131-136.

14. Shirley, D. G., and J. Skinner. 1978. Acute compensatory adaptation of renal function following contralateral kidney exclusion in Brattleboro rats with diabetes insipidus. J. Physiol. (Lond.). 283:425-438.

15. Fine, L. G., W. Trizna, J. J. Bourgoignie, and N. S Bricker. 1978. Functional profile of the isolated uremic nephron. Role of compensatory hypertrophy in the control of fluid reabsorption by the proximal straight tubule. J. Clin. Invest. 61:1508-1518.

16. Trizna, W., N. Yanagawa, Y. Bar-Khayim, B. Houston, and L. G. Fine. 1981. Functional profile of the isolated uremic nephron. Evidence of proximal tubular "memory" in experimental renal disease. J. Clin. Invest. 68:760-767.

17. Baylis, C., and B. M. Brenner. 1978. Mechanism of the glucocorticoid-induced increase in glomerular filtration rate. Am. J. Physiol. 234:F166-F170.

18. Bratton, A. D., and E. K. Marshall. 1939. A new coupling component for sulfanilamide determination. J. Biol. Chem. 128:537-550.

19. Führ, J., J. Kaczmarszyk, and C. D. Krüttgen. 1955. Ein einfache colorimetrische Methode zur Inulin Bestimmung für Nierenclearanceuntersuchungen bei Stoffwechselgesunden und Diabetikern. Klin. Wochschr. 33:729-730.

20. Iino, Y., and M. B. Burg. 1979. Effect of parathyroid hormone on bicarbonate absorption by proximal tubules in vitro. Am. J. Physiol. 236:F387-F391.

21. Burg, M. B., and J. Orloff. 1968. Control of fluid absorption in the renal proximal tubule. J. Clin. Invest. 47:2016-2024.

22. Snedecor, G. W., and W. G. Cochran. 1967. Statistical methods. 6th Edition. Iowa State University Press, Ames, Iowa.

23. Bailey, B. J. R. 1977. Tables of the Bonferroni t statistic. J. Am. Statistical Assoc. 72:469-477.

24. Malt, R. A. 1969. Compensatory growth of the kidney. N. Engl. J. Med. 280:1446-1459.

25. Brazy, P. C., J. W. McKeown, R. H. Harris, and V. W. Dennis. 1980. Comparative effects of dietary phosphate, unilateral nephrectomy and parathyroid hormone on phosphate transport by the rabbit proximal tubule. Kidney Int. 17:788-800.

26. Harris, R. H., and C. F. Best. 1977. Circulatory retention of urinary growth factors as a stimulus to renal growth. Kidney Int. 12:305-312.

27. Obertop, H., and R. A. Malt. 1977. Lost mass and excretion as stimuli to parabiotic compensatory renal hypertrophy. Am. J. Physiol. 232:F405-F408.

28. Knepper, M. A., and M. B. Burg. 1981. Increased fluid absorption and cell volume in isolated rabbit proximal straight tubules after in vivo DOCA administration. $A \boldsymbol{m}$. J. Physiol. 241:F502-F508.

29. Diezi, J., P. Michoud, A. Grandchamp, and G. Giebisch. 1976. Effects of nephrectomy on renal salt and water transport in the remaining kidney. Kidney Int. 19:450462.

30. Halliburton, I. W., and R. Y. Thomson. 1965. Chemical aspects of compensatory renal hypertrophy. Cancer Res. 25:1882-1887.

31. Toback, F. G., and L. M. Lowenstein. 1974. Thymidine metabolism during normal and compensatory renal growth. Growth. 38:35-44.

32. Toback, F. G., P. D. Smith, and L. M. Lowenstein. 1974 Phospholipid metabolism in the initiation of renal compensatory growth after reduction of renal mass. J. Clin. Invest. 54:91-97.

33. Coe, F. L., and P. R. Korty. 1967. Protein synthesis during compensatory renal hypertrophy. Am. J. Physiol. 213:2585-2589.

34. Johnson, H. A., and J. M. Vera-Roman. 1966. Compensatory renal enlargment. Hypertrophy versus hyperplasia. Am. J. Pathol. 49:1-13.

35. Fine, L. G., E. P. Nord, and T. Bradley. The nature of the adaptive response of the proximal tubule brush border membrane in the remnant kidney. 1983. Kidney Int. 23:213. (Abstr.) 